\title{
Article \\ Major Ion Toxicity to Glochidia of Common and Imperiled Freshwater Mussel Species
}

\author{
Robert B. Bringolf ${ }^{1,2, *}$, Brenna K. Raines ${ }^{1}$, Robert E. Ratajczak ${ }^{1}$ and David Lee Haskins ${ }^{1,2,3}$ \\ 1 Warnell School of Forestry and Natural Resources, University of Georgia, Athens, GA 30605, USA; \\ bsraines@usgs.gov (B.K.R.); bobrat@uga.edu (R.E.R.); dlhaskin@purdue.edu (D.L.H.) \\ 2 Interdisciplinary Toxicology Program, University of Georgia, Athens, GA 30605, USA \\ 3 Savannah River Ecology Lab, University of Georgia, Aiken, SC 29802, USA \\ * Correspondence: bringo@uga.edu
}

Citation: Bringolf, R.B.; Raines, B.K.; Ratajczak, R.E.; Haskins, D.L. Major Ion Toxicity to Glochidia of Common and Imperiled Freshwater Mussel Species. Diversity 2022, 14, 95. https://doi.org/10.3390/d14020095 Academic Editors: Michael Wink, Luc Legal, Ben-Erik Van Wyk and Michel Baguette

Received: 14 January 2022 Accepted: 25 January 2022

Published: 28 January 2022

Publisher's Note: MDPI stays neutral with regard to jurisdictional claims in published maps and institutional affiliations.

Copyright: (C) 2022 by the authors. Licensee MDPI, Basel, Switzerland. This article is an open access article distributed under the terms and conditions of the Creative Commons Attribution (CC BY) license (https:/ / creativecommons.org/licenses/by/ $4.0 /)$.

\begin{abstract}
Freshwater mussel taxa are severely imperiled and among the most sensitive to several contaminants, including chloride. Relatively little is known of the toxicity of major ions to glochidia (larvae), particularly for rare species, or the effects of hardness on major ion toxicity to glochidia. Therefore, the primary objectives of this work were to: (1) determine the acute toxicity of major ion salts to glochidia, (2) compare chloride sensitivity of glochidia from common and rare species, and (3) evaluate the relationship between water hardness and chloride toxicity to glochidia. We assessed $24 \mathrm{~h}$ EC50s for fatmucket (Lampsilis siliquoidea) glochidia exposed to $\mathrm{NaCl}, \mathrm{KCl}, \mathrm{MgCl}_{2}$, $\mathrm{CaCl}_{2}, \mathrm{Na}_{2} \mathrm{SO}_{4}, \mathrm{MgSO}_{4}, \mathrm{CaSO}_{4}$, and $\mathrm{NaHCO}_{3}$ in moderately hard water. We determined $\mathrm{NaCl} \mathrm{EC} 50$ s for four species and $\mathrm{KCl}$ EC50s for glochidia of three species. Toxicity of chloride was generally consistent among the various chloride salts except for $\mathrm{KCl}$, which was more toxic than all others by 1-2 orders of magnitude. Our results suggest that commonly tested species may be generally representative of rare species. Water hardness ameliorated the toxicity of chloride for all species to varying degrees. Results of this work indicate that some existing water quality criteria that do not include mussel toxicity data may not be protective of freshwater mussels.
\end{abstract}

Keywords: chloride; hardness; Unionidae; sensitivity

\section{Introduction}

In North America and elsewhere, water pollution from major ions $\left(\mathrm{Na}^{+}, \mathrm{K}^{+}, \mathrm{Ca}^{2+}\right.$, $\mathrm{Mg}^{2+}, \mathrm{Cl}^{-}, \mathrm{SO}_{4}^{-}, \mathrm{HCO}_{3}{ }^{-}$) stems largely from anthropogenic activities such as mineral mining, oil and gas extraction, irrigation, industrial effluents, and road deicing [1,2]. Major ion pollution can cause osmotic stress and increased metabolic costs in freshwater organisms $[3,4]$, posing a threat to fish and aquatic invertebrates such as freshwater mussels [5-10]. Freshwater mussels (family Unionidae) are well documented among the most imperiled of aquatic species [11] and toxicity studies with early life stages of freshwater mussels exposed to major ions have demonstrated that glochidia (larvae) and juveniles are among the most sensitive of all species tested [5,10,12-16].

Glochidia exposed to high concentrations of major ions close their valves or suffer ionoregulatory disturbance rendering them unable to attach to the host fish required to complete their parasitic lifecycle [7]. Field studies corroborate lab toxicity testing; in the Clinch and Powell River systems in Tennessee, USA, declining mussel richness and density has been connected with rising concentrations of major ions from coal mining operations [15]. Similarly, in Ontario, Canada, stream salinization from road salt application during the winter resulted in elevated glochidia mortality [5,9].

The high sensitivity of mussels to some contaminants (e.g., ammonia, chloride, copper, cadmium) has resulted in revisions of some state and federal water quality guidelines for the protection of aquatic life. For example, in 2013 the US Environmental Protection Agency (USEPA) Water Quality Criteria for ammonia was updated based on mussel (and 
snail) toxicity data, and in 2011, the Canadian Water Quality Guidelines for chloride were updated to be protective of mussels. Although existing data indicate that at least some types of major ion pollution pose a significant threat to freshwater mussels, to date only a few of the most common species have been evaluated and with the most common salts (i.e., $\mathrm{NaCl}$ ); little is known about the sensitivity of rare mussel species, or the effects of various pairings of cations and anions.

The goal of the present study was to evaluate the relative risks of major ions to common and imperiled freshwater mussel species to better inform derivation of water quality guidelines for protection of aquatic species. Therefore, we conducted standardized acute toxicity tests with major ion salts and glochidia from four species: Lampsilis siliquoidea, L. fasciola, Hamiota altilis, and Anodonta suborbiculata. For L. siliquoidea and L. fasciola, we obtained glochidia from two geographically distinct populations. L. siliquoidea, commonly known as the fatmucket, is currently one of the most commonly used freshwater mussel species for toxicity tests and has a wide distribution in North America with secure populations throughout its range (http: / / explorer.natureserve.org/servlet/NatureServe?searchName= Lampsilis+siliquoidea; last accessed 15 October 2021).

L. fasciola, the wavy-rayed lampmussel, was designated as a Species of Special Concern in Canada [17] but otherwise has a wide distribution and secure status in the United States [18]. H. altilis, commonly known as the finelined pocketbook, is endemic to the eastern reaches of the Mobile basin in Alabama, Georgia, and Tennessee, and historically in Mississippi. Decreasing range and declining populations resulted in $H$. altilis being listed as Threatened 1993 by the US Fish \& Wildlife Service and as Endangered on the IUCN Red List [19]. Anodonda suborbiculata, the flat floater, is broadly distributed across the US and is characterized as having stable or expanding populations (http:// explorer.natureserve.org/servlet/NatureServe?searchName=Anodonta+suborbiculata; last accessed 15 October 2021).

\section{Materials and Methods}

\subsection{Test Organisms}

Gravid adult female L. siliquoidea were obtained from captive populations maintained by the Kentucky Department of Fish and Wildlife Resources Center for Mollusk Conservation (Frankfort, KY, USA) (heretofore referred to as L. siliquoidea KY) and Missouri State University at the Kansas City Zoo (heretofore referred to as L. siliquoidea MO). Gravid adult female $L$. fasciola glochidia were obtained from captive populations maintained at the Alabama Aquatic Biodiversity Center (Marion, AL, USA) operated by the Alabama Department of Conservation and Natural Resources (heretofore referred to as L. fasciola AL) and from the Conservation Aquaculture Center (Marion, NC, USA) operated by the North Carolina Wildlife Resources Commission (heretofore referred to as L. fasciola NC). Gravid female $H$. altilis were also obtained from the Alabama Aquatic Biodiversity Center (Marion, AL, USA). Gravid female A. suborbiculata were obtained from culture ponds at Auburn University (Auburn, AL, USA).

The female mussels were transported in coolers with $10 \mathrm{~L}$ of their source water to the Aquatic Biology and Ecotoxicology Lab at the University of Georgia, where they were acclimated to dechlorinated tap water over $24-48 \mathrm{~h}$ and then placed in a Living Stream (Frigid Units, Inc., Toledo, $\mathrm{OH}$, USA) with dechlorinated tap water at $17{ }^{\circ} \mathrm{C}$. Mussels were fed every other day with a prepared algal diet [20]. All mussels were maintained for 1-2 weeks in the Living Stream prior to obtaining glochidia for testing.

Consistent with ASTM [20] guidelines for toxicity testing with mussel early life stages, viability was determined for glochidia from each female mussel prior to pooling the glochidia for distribution into the test beakers. Briefly, the glochidia were obtained from individual females ( $n=3$ to 6 ) by using a syringe filled with culture water to gently rupture the marsupial gills and flush the glochidia from a single female into a $1 \mathrm{~L}$ beaker with approximately $300 \mathrm{~mL}$ of culture water. Glochidia were gently suspended with a $100 \mathrm{~mL}$ pipette while 10 subsamples of $200 \mu \mathrm{L}$ each were collected and placed on a petri dish. Each 
$200 \mu \mathrm{L}$ drop was observed under a stereomicroscope (Leica MZ12, Leica Microsystems, Wetzlar, Germany) to determine the number of open and closed glochidia prior to addition of a drop of saturated $\mathrm{NaCl}$ solution, and again $60 \mathrm{~s}$ after the $\mathrm{NaCl}$ was added. Viability was calculated using the following equation: percent viability $=$ (number closed after $\mathrm{NaCl}$ - number closed before $\mathrm{NaCl}$ )/(number closed after $\mathrm{NaCl}+$ number closed before $\mathrm{NaCl}$ ) * 100. Roughly equal numbers (within 2-fold) of glochidia were pooled from the various females with viability $>80 \%$.

\subsection{Test Chemicals and Target Concentrations}

All test chemicals (salts) were certified ACS grade purchased from Fisher Scientific unless otherwise specified. Chloride salts included sodium chloride $(\mathrm{NaCl},>99.0 \%$ purity, 7647-14-5), magnesium chloride $\left(\mathrm{MgCl}_{2} \cdot 6 \mathrm{H}_{2} \mathrm{O}, 99 \%\right.$ purity, CAS 7791-18-6), potassium chloride ( $\mathrm{KCl},>99.0 \%$ purity, CAS $7447-40-7)$, and calcium chloride $\left(\mathrm{CaCl}_{2} \cdot 2 \mathrm{H}_{2} \mathrm{O}, 99 \%\right.$ purity, CAS 10035-04-8). Sulfate salts included sodium sulfate $\left(\mathrm{Na}_{2} \mathrm{SO}_{4},>99.0 \%\right.$ purity, CAS 7757-82-6), magnesium sulfate $\left(\mathrm{MgSO}_{4}\right.$, certified grade, CAS 7487-88-9), and calcium sulfate $\left(\mathrm{CaSO}_{4} \cdot 2 \mathrm{H}_{2} \mathrm{O},>98 \%\right.$ purity, CAS $\left.10101-41-4\right)$.

Target test concentrations were based on literature for acute toxicity tests with other taxa (e.g., fish, cladocerans) and salt solubility limits. Target treatment levels for all toxicity tests (all mussel species and hardness levels) with $\mathrm{NaCl}, \mathrm{MgCl}_{2}, \mathrm{CaCl}_{2}, \mathrm{Na}_{2} \mathrm{SO}_{4}$, and $\mathrm{MgSO}_{4}$ were control, $0.625,1.25,2.5,5.0$, and $10.0 \mathrm{~g}$ of salt/ $\mathrm{L}$ added to test water. Target test concentrations for $\mathrm{CaSO}_{4}$ were lower due to solubility limits and included: control, 0.125 , $0.25,0.5,1.0,2.0 \mathrm{~g}$ salt/L. Target test concentrations for $\mathrm{KCl}$ were control, 0.0063, 0.0125, $0.025,0.05$, and $0.1 \mathrm{~g}$ salt/L. Controls consisted of reconstituted water only, as described for each test below.

\subsection{Glochidia Toxicity Test Methods}

All experiments followed established methodology for conducting toxicity tests with early life stages of freshwater mussels [20]. Briefly, all toxicity tests consisted of six treatments (see above) with three replicates per treatment for a total of 18 experimental units, each consisting of 500-1000 glochidia in $100 \mathrm{~mL}$ of test solution in a $150 \mathrm{~mL}$ glass beaker. All replicates were randomized in a water bath maintained at $20^{\circ} \mathrm{C}$ under ambient laboratory light at 14:10 h light:dark. Test solutions were not renewed during the test and glochidia viability was assessed as described previously in a sample of 100-200 glochidia at $24 \mathrm{~h}$. Water samples $(10 \mathrm{~mL})$ were collected from the highest test concentration at the start of each test and acidified $(\mathrm{pH}<2)$ and stored at $4{ }^{\circ} \mathrm{C}$ until analysis of appropriate target ions at the University of Georgia Center for Applied Isotope Studies where target cations $\left(\mathrm{Na}^{+}, \mathrm{K}^{+}\right.$, $\mathrm{Mg}^{2+}, \mathrm{Ca}^{2+}$ ) were measured by inductively coupled plasma mass spectrometry (ICP-MS) and anions $\left(\mathrm{Cl}^{-}, \mathrm{SO}_{4}{ }^{-}\right)$were measured by ion chromatography. Water quality parameters (temperature, dissolved oxygen, $\mathrm{pH}$ ) were measured at the beginning of each test in one randomly selected replicate from each treatment. Hardness and alkalinity of the dilution water for each test were measured with standard titration methods [21].

Survival in each test concentration was corrected for mortality in the controls. Data analysis was performed to determine the EC50 (median effect concentration) with the Toxicity Relationship Analysis Program (TRAP; https: / /archive.epa.gov/med/med_archive_ 03/web/html/trap.html; last accessed 20 July 2021).

\subsection{Toxicity of Chloride and Sulfate Salts to Lampsilis siliquoidea}

We evaluated the toxicity of chloride salts (sodium chloride, magnesium chloride, calcium chloride, and potassium chloride) and sulfate salts (sodium sulfate, magnesium sulfate, and calcium sulfate) to L. siliquoidea (MO) glochidia. Toxicity of sodium chloride was also assessed with L. siliquoidea (KY) for comparison among geographically distinct populations. Pooled initial viability for the MO population $(n=4)$ was $84.0 \%$ and the KY population $(n=4)$ was $93.1 \%$. All tests were conducted in moderately hard reconstituted water [22]. 


\subsection{Species Sensitivity Comparison for Chloride Salts}

We compared toxicity of chloride salts $(\mathrm{NaCl}$ and $\mathrm{KCl})$ to glochidia of common and rare mussel species, and in some cases, the same species obtained from distinct populations (i.e., different states). $\mathrm{NaCl}$ toxicity was assessed with L. siliquoidea (KY and $\mathrm{MO}$ ), L. fasciola (NC and AL), A. suborbiculata, and H. altilis. Toxicity of $\mathrm{KCl}$ was evaluated with L. siliquoidea (MO), L. fasciola (AL), and H. altilis. All tests were conducted in moderately hard reconstituted water [22].

\subsection{Water Hardness Effects on Chloride Toxicity}

We assessed the effects of water hardness on chloride $(\mathrm{NaCl})$ toxicity in glochidia of three species: L. siliquoidea (KY), L. fasciola (NC and AL), and A. suborbiculata. Test water hardness categories included soft $(0-60 \mathrm{mg} \mathrm{CaCO} / \mathrm{L})$, moderately hard (61-120 mg $\left.\mathrm{CaCO}_{3} / \mathrm{L}\right)$, hard (121-180 mg CaCO $\left.3 / \mathrm{L}\right)$, and very hard (181-300 $\left.\mathrm{mg} \mathrm{CaCO}_{3} / \mathrm{L}\right)$ as characterized by USGS (https: / / water.usgs.gov / owq/hardness-alkalinity.html; last accessed 26 May 2020), with an additional category for extremely hard ( $\geq 301 \mathrm{mg} \mathrm{CaCO} / \mathrm{L})$. Test water hardness was established by proportionally adjusting the amounts of the five salts used to create moderately hard reconstituted water, as described by Smith et al. [22]. Tests with $L$. siliquoidea and A. suborbiculata were performed at all five hardness levels; tests with L. fasciola (NC and AL) were conducted at all levels except extremely hard due to insufficient numbers of glochidia.

\section{Results}

\subsection{Glochidia Viability, Water Quality Parameters, and Ion Concentrations}

Pooled initial glochidia viability before testing was above $80 \%$ for all samples and ranged from 84 to $93.2 \%$. Water quality parameters were within acceptable ranges for all toxicity tests: temperature ranged from $19.7-20.2{ }^{\circ} \mathrm{C}$, dissolved oxygen ranged from $7.68-9.45 \mathrm{mg} / \mathrm{L}$, and $\mathrm{pH}$ ranged from 7.68-8.32. Measured anion concentrations of test salts averaged $96.0( \pm 7.3 \%, n=22)$ of target concentrations. Consistent with test guidelines [20], control survival was $\geq 90 \%$ for all tests.

\subsection{Toxicity of Chloride and Sulfate Salts to L. siliquoidea}

Median effective concentrations (24-h EC50) of chloride salts to L. siliquoidea ranged from $2.47 \mathrm{~g} / \mathrm{L}$ to $3.6 \mathrm{~g} / \mathrm{L}$ for all chloride salts except $\mathrm{KCl}$, which had an EC50 of $0.056 \mathrm{~g} / \mathrm{L}$ (Figure 1). Toxicity of sulfate salts was generally similar to chloride salts (other than $\mathrm{KCl}$ ) (Figure 1). The EC50 for $\mathrm{Na}_{2} \mathrm{SO}_{4}$ was $5.32 \mathrm{~g}$ salt/L (4.93-5.78) and $\mathrm{MgSO}_{4}$ was $3.52 \mathrm{~g}$ salt/L (3.20-3.85). An EC50 for $\mathrm{CaSO}_{4}$ could not be calculated because of low mortality in the highest treatment concentrations, so it was reported as $>2.0 \mathrm{~g}$ salt $/ \mathrm{L}$, which was the highest concentration tested and it approached solubility limits. The difference in $\mathrm{NaCl}$ EC50s between the two L. siliquoidea populations (MO, $2.47 \mathrm{~g} / \mathrm{L}$ and $\mathrm{KY}, 3.60 \mathrm{~g} / \mathrm{L})$ exceeded the variability in $\mathrm{EC} 50$ s for to $\mathrm{NaCl}, \mathrm{MgCl}_{2}$, and $\mathrm{CaCl}_{2}$ within a single (MO) population.

\subsection{Species Sensitivity Comparison for Chloride Salts}

$\mathrm{NaCl} 24-\mathrm{hr}$ EC50s varied among the four species by a factor of 2.4 (Figure 2); the lowest EC50 was $1.56 \mathrm{~g} / \mathrm{L}$ (1.33-1.80) for L. fasciola (AL), and the highest was $3.60 \mathrm{~g} / \mathrm{L}$ for L. siliquoidea (KY). The Federally Threatened species, H. altilis, had an EC50 of $2.42 \mathrm{~g} / \mathrm{L}$ (2.11-2.77), near the geometric mean $(n=6)$ of $2.36 \mathrm{~g} / \mathrm{L}$. Within species, $\mathrm{NaCl}$ EC50s for the two L. siliquoidea populations ( $\mathrm{MO}, 2.47 \mathrm{~g} / \mathrm{L}$ and $\mathrm{KY}, 3.60 \mathrm{~g} / \mathrm{L}$ ) varied more than the two L. fasciola populations (AL, $1.56 \mathrm{~g} / \mathrm{L}$ and $\mathrm{NC}, 1.95 \mathrm{~g} / \mathrm{L}$ ), but neither species varied by more than 1.5 -fold. 


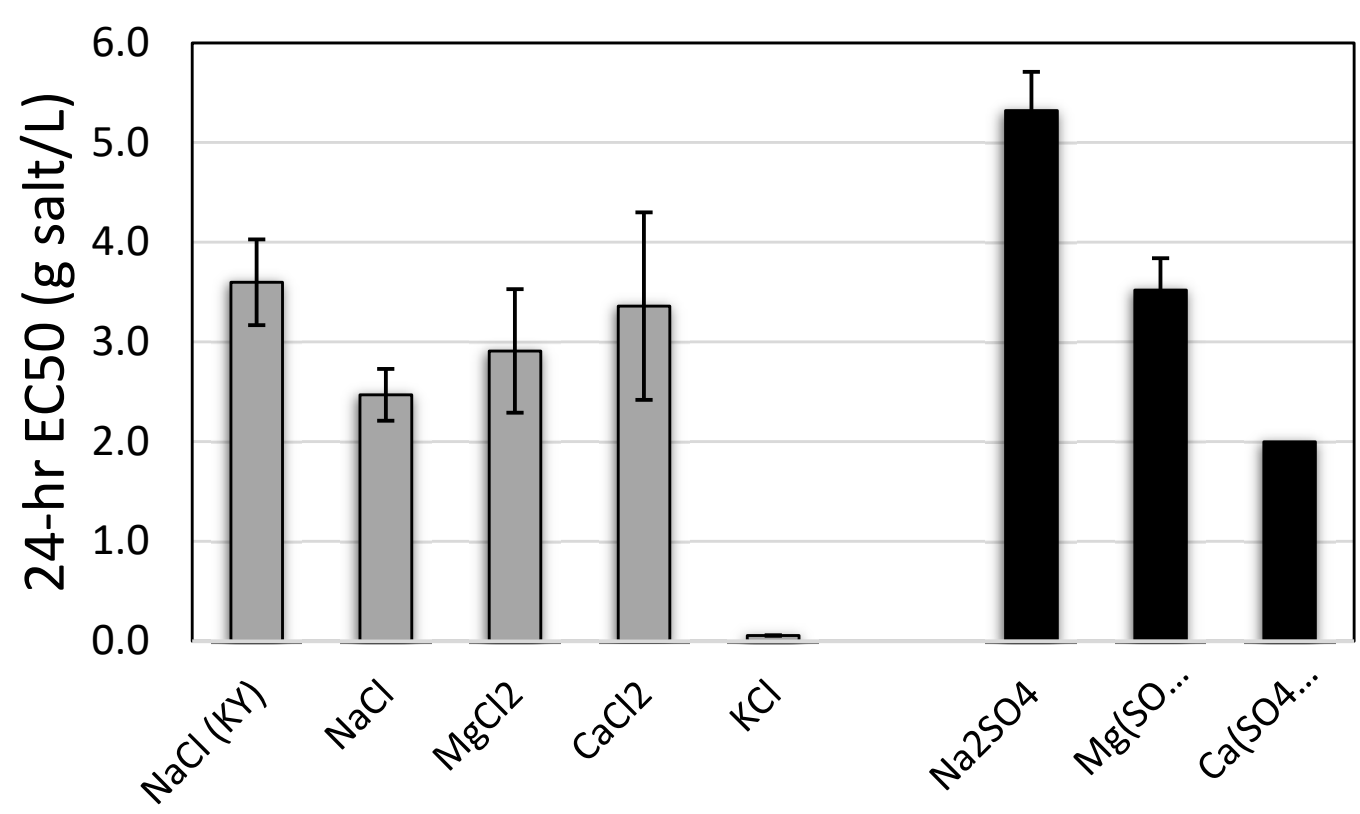

Figure 1. Twenty-four-hour EC50s for Lampsilis siliquoidea glochidia exposed to chloride (gray bars) or sulfate (black bars) salts in moderately hard water (hardness $80-90 \mathrm{mg} / \mathrm{L}$ ) at $20{ }^{\circ} \mathrm{C}$. Origin of glochidia was Missouri, USA, except for one batch noted from Kentucky (KY). Error bars represent 95\% confidence limits.

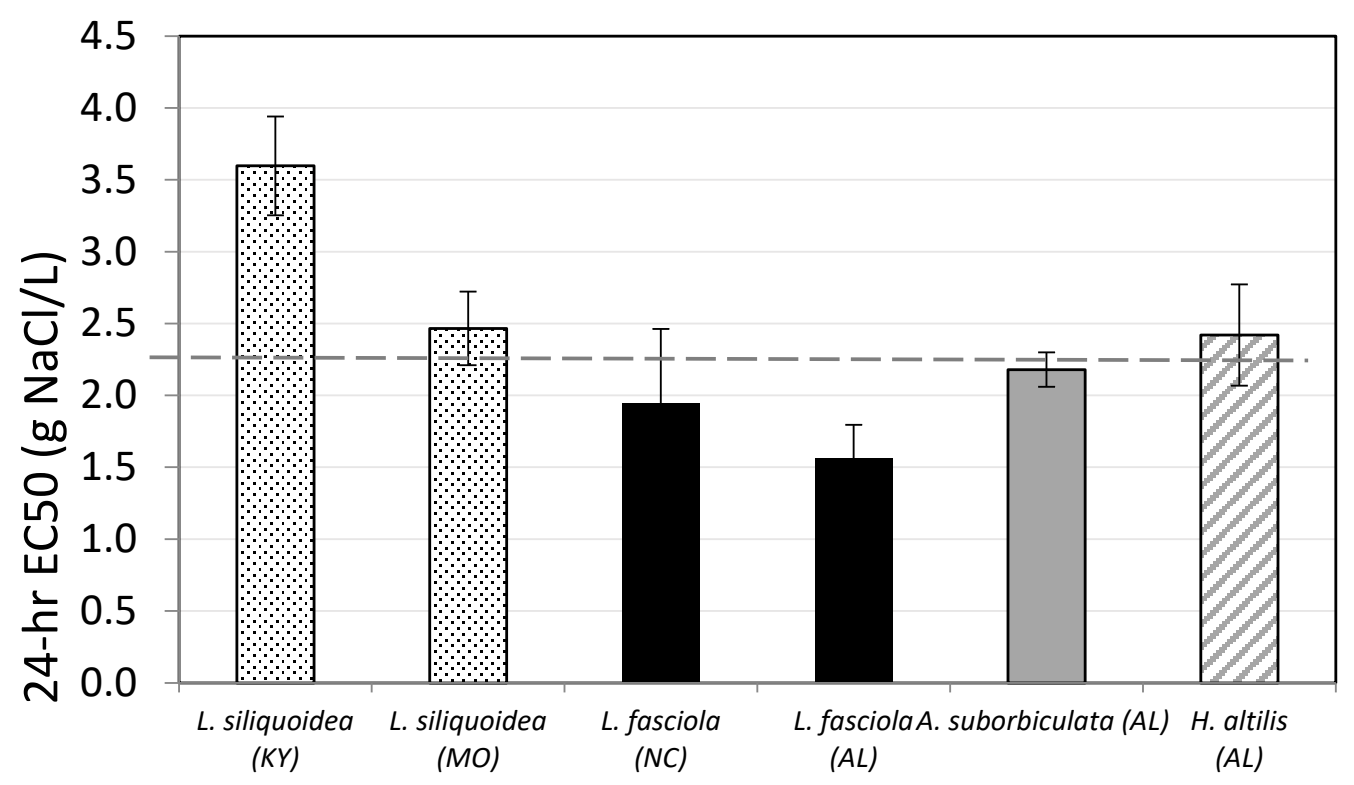

Figure 2. Twenty-four-hour $\mathrm{NaCl}$ EC50s for glochidia from Lampsilis siliquoidea, L. fasciola, Anodonta suborbiculata, and Hamiota altilis (state of origin in parenthesis). All tests were conducted in moderately hard reconstituted water (hardness $80-90 \mathrm{mg} / \mathrm{L}$ ) at $20^{\circ} \mathrm{C}$. The dashed line indicates the geometric mean of the EC50s for the six tests. Error bars represent $95 \%$ confidence limits.

Toxicity of $\mathrm{KCl}$ was generally similar among the three species tested, varying by a factor of 1.3 (Figure 3). The $24 \mathrm{~h}$ EC50s ranged from a low of $0.040 \mathrm{~g} / \mathrm{L}(0.037-0.043)$ in H. altilis to $0.053 \mathrm{~g} / \mathrm{L}(0.048-0.057)$ in L. siliquoidea, with a geometric mean $(n=3)$ of $0.046 \mathrm{~g} / \mathrm{L}$. 


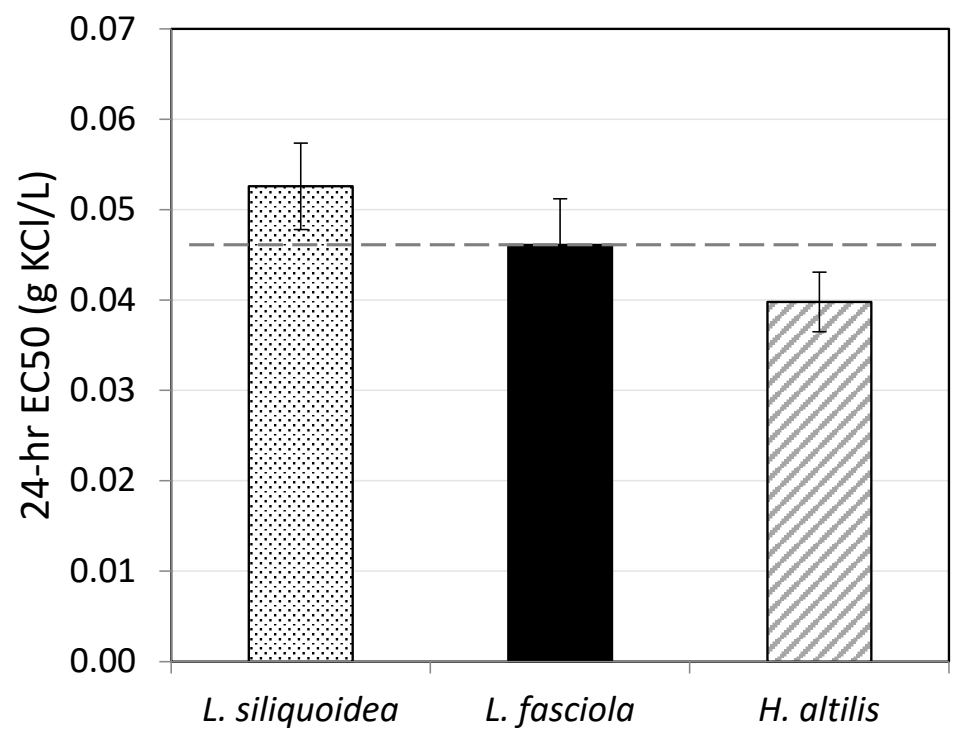

Figure 3. Twenty-four-hour $\mathrm{KCl} \mathrm{EC50s} \mathrm{for} \mathrm{glochidia} \mathrm{from} \mathrm{Lampsilis} \mathrm{siliquoidea,} \mathrm{L.} \mathrm{fasciola,} \mathrm{and} \mathrm{Hamiota}$ altilis. All tests were conducted in moderately hard reconstituted water (hardness 80-90 mg/L) at $20{ }^{\circ} \mathrm{C}$. The dashed line indicates the geometric mean of the EC50s for the three species. Error bars represent $95 \%$ confidence limits.

\subsection{Water Hardness Effects on Sodium Chloride Toxicity}

For glochidia from all three species (L. siliquoidea, L. fasciola, and A. suborbiculata), the lowest $\mathrm{NaCl}$ EC50s occurred in the softest water (Figure 4). Toxicity generally decreased with increasing water hardness, at least to a point. For example, the $24 \mathrm{~h} \mathrm{NaCl} \mathrm{EC50} \mathrm{for}$ L. siliquoidea was lowest at $2.70 \mathrm{~g} / \mathrm{L}$ in water with hardness $42 \mathrm{mg} / \mathrm{L}$ as $\mathrm{CaCO}_{3}$ and the EC50 increased by 2.24-fold to $6.06 \mathrm{~g}$ salt/ $\mathrm{L}$ at a hardness of $168 \mathrm{mg} / \mathrm{L}$ as $\mathrm{CaCO}_{3}$, though at a hardness of $464 \mathrm{mg} / \mathrm{L}$ as $\mathrm{CaCO}_{3}$ the $\mathrm{EC} 50$ was $3.57 \mathrm{~g}$ salt/L (Figure 4). A similar trend generally occurred with A. suborbiculata but the highest EC50s (Approx. $5.8 \mathrm{~g}$ salt/L) were not reached until the highest hardness levels of 310 and $548 \mathrm{mg} \mathrm{CaCO} 3 / \mathrm{L}$, with no decline of EC50 at the highest hardness level. The trend for a protective effect of hardness on $\mathrm{NaCl}$ toxicity was similar but less pronounced for the $L$. fasciola $(\mathrm{NC})$ population with $\mathrm{NaCl}$ EC50s increasing 2.5-fold from a low of $1.31 \mathrm{~g} / \mathrm{L}$ at a hardness of $43 \mathrm{mg} / \mathrm{L}$ as $\mathrm{CaCO}_{3}$ to a high of $3.21 \mathrm{~g} / \mathrm{L}$ at a hardness of $302 \mathrm{mg} / \mathrm{L}$ as $\mathrm{CaCO}_{3}$, which was the highest hardness level tested for this species.

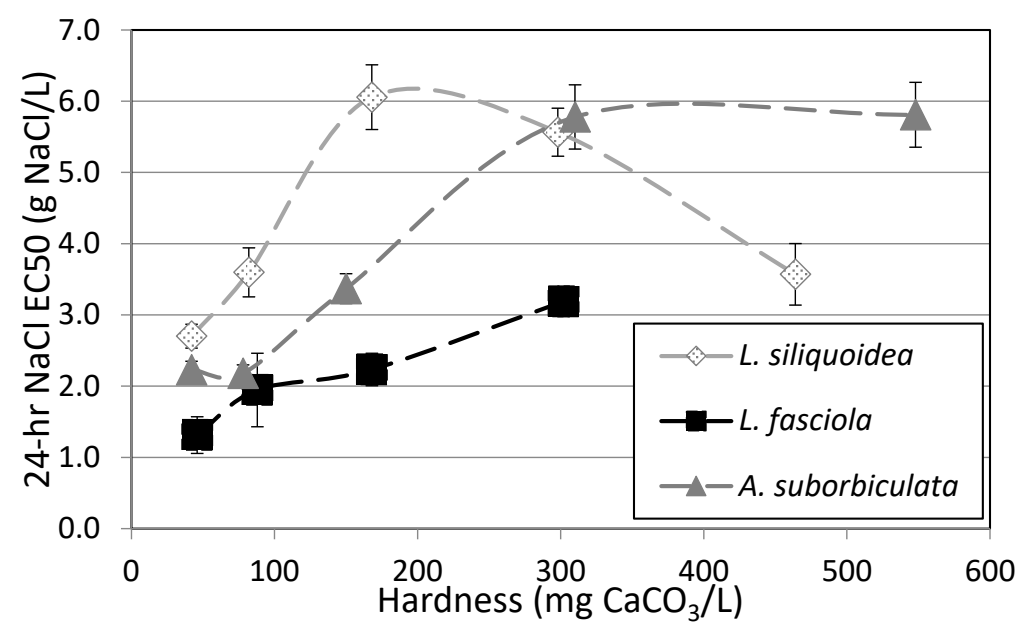

Figure 4. Effect of water hardness on $24 \mathrm{~h} \mathrm{NaCl} \mathrm{EC50s} \mathrm{for} \mathrm{glochidia} \mathrm{from} \mathrm{Lampsilis} \mathrm{siliquoidea,}$ L. Fasciola, and Anodonta suborbiculata. Error bars represent the upper and lower $95 \%$ confidence limits. Dashed lines indicate general trends and are not fitted regression lines. 


\section{Discussion}

\subsection{Toxicity of Chloride and Sulfate Salts to Glochidia}

Acute toxicity tests with salts of chloride and sulfate revealed that freshwater mussel glochidia are sensitive to these major ions, consistent with results from previous glochidia ion toxicity research $[5,9,12]$ as well as ion testing with juvenile mussels [16]. Among chloride toxicity tests in the present study, glochidia were substantially more sensitive to $\mathrm{KCl}$ than other chloride salts, consistent with juvenile mussel $\mathrm{KCl}$ toxicity test results [16], suggesting that potassium may be highly regulated in mussel physiology. While chloride has been the focus in previous studies on freshwater mussel major ion sensitivity $[5,14]$, this differential toxicity among chloride salts also suggests that the cations (e.g., calcium, sodium, magnesium, and potassium) of the salts studied should be taken into consideration when evaluating acute toxicity of major anions like chloride and sulfate. Similar trends have been reported for other freshwater organisms such as fish and cladocerans [23], and the approximate order of chloride salt toxicity is $\mathrm{KCl}>\mathrm{MgCl}_{2}>\mathrm{CaCl}_{2}>\mathrm{NaCl}$.

The similarity in sensitivity among the four species tested with $\mathrm{NaCl}$ and among the three species tested with $\mathrm{KCl}$ suggests that glochidia of different unionid species may be similar in their tolerance to at least some major ions. Hamiota altilis, the federally threatened species, was the most sensitive of the three species tested with $\mathrm{KCl}$, but $H$. altilis sensitivity to $\mathrm{NaCl}$ was near the mean of the four species (six tests). Additional testing is warranted to determine if other rare species are more sensitive to major ions. For $\mathrm{NaCl}$, the variability in sensitivity between different populations of the same species was more limited than the overall variability among species. Unfortunately, insufficient numbers of glochidia were available to perform similar comparisons with different populations and other salts.

Not only was sensitivity to $\mathrm{NaCl}$ similar among the four species of glochidia we tested, but it was also similar to the range of sensitivity reported for juvenile mussels of a variety of species ([16] Figure 5). Like juveniles, glochidia are among the most sensitive organisms tested to date with $\mathrm{NaCl}$ ([16] Figure 5). Similarly, our tests with glochidia from three species demonstrated that glochidia are the most sensitive organisms tested to date with $\mathrm{KCl}$, and glochidia appear to be about an order of magnitude more sensitive to $\mathrm{KCl}$ than juvenile mussels ([16] Figure 6). These findings suggest that glochidia would drive any potential water quality criteria derivation for potassium or $\mathrm{KCl}$.

\subsection{Effect of Water Hardness on Chloride Sensitivity}

Chloride $(\mathrm{NaCl})$ toxicity tests at a range of water hardness in the present study suggested that mussels residing in naturally hard waters may be afforded some protection against major ion toxicity; however, further testing is needed to confirm this finding. These results are consistent with hardness testing results from major ion tests with other commonly tested taxa $[24,25]$. However, the protective effect of hardness to glochidia may be limited; L. siliquoidea glochidia in the present study demonstrated greater sensitivity to $\mathrm{NaCl}$ as hardness exceeded the very hard $\left(170 \mathrm{mg} / \mathrm{L}\right.$ as $\left.\mathrm{CaCO}_{3}\right)$ range. This toxicity should not be surprising because hardness is comprised primarily of $\mathrm{Ca}$ and $\mathrm{Mg}$, which caused toxicity in the $\mathrm{g} / \mathrm{L}$ range to glochidia in our other tests when paired with chloride and sulfate. Greater buffering of toxicity by hardness may be possible with longer acclimation periods with high hardness water, but unfortunately glochidia remain viable outside of the adult female for only a few days [26], so long acclimation periods (days) prior to testing are not feasible with $24 \mathrm{~h}$ toxicity tests. One possibility is to acclimate brooding females in harder waters for long periods prior to obtaining glochidia for testing.

\subsection{Implications}

The current USEPA criterion maximum (short-term) concentration for chloride is $860 \mathrm{mg} \mathrm{Cl}^{-} / \mathrm{L}$ and the criterion continuous (long-term) concentration for chloride is $230 \mathrm{mg} \mathrm{Cl}^{-} / \mathrm{L}$ [27]. Derivation of these criteria did not include freshwater mussel toxicity data, largely because standardized freshwater mussel toxicity testing guidelines were not available at the time of the derivation in 1988. Current Canadian Water Quality Guidelines 
for Chloride were published in 2011 and included glochidia and juvenile mussel toxicity data [28]. As expected, these criteria are lower than USEPA criteria, with a short-term exposure limit of $640 \mathrm{mg} \mathrm{Cl}^{-} / \mathrm{L}$ and a long-term exposure limit of $120 \mathrm{mg} \mathrm{Cl}^{-} / \mathrm{L}$. In the present study, chloride ( $\mathrm{NaCl}) \mathrm{EC} 50$ for L. fasciola was $590 \mathrm{mg} \mathrm{Cl}^{-} / \mathrm{L}$ in soft water and $938 \mathrm{mg} \mathrm{Cl}^{-} / \mathrm{L}$ in moderately hard water, suggesting that current EPA chloride criteria may not adequately protect this species in softer waters. These EC50 values are similar to previous reports for toxicity of $\mathrm{NaCl}$ to a closely related species, L. siliquoidea $[5,12]$.

Additional research to further characterize freshwater mussel sensitivity to major ions is needed to advance understanding of freshwater mussel declines in North America and elsewhere. Among other needs, testing with more species to better represent the approximately 300 extant species in North America is a high priority. Furthermore, comparisons of sensitivity of populations from different regions throughout a species' range are rare and more of these types of tests would likely help explain some of the variability in sensitivity among tests with the same species. Based on our findings, some of this variability may also be attributed to water quality, particularly hardness, of the sites where mussels are collected for testing. Additionally, little is known about the variability in sensitivity of glochidia that are collected at different times of the year. For example, some species, such as those of the genus Lampsilis, brood glochidia nearly year-round, whereas other species brood for only a few weeks out of the year. Few studies have compared the sensitivity of glochidia collected early in their brooding period to those collected near the end of the period, but Fritts et al. [29] reported that L. cardium glochidia collected early in their brooding period were significantly less sensitive to $\mathrm{NaCl}$ than those collected late in the brooding period. Tests that utilize the most sensitive life stages would be most protective of natural populations.

Beyond additional laboratory toxicity testing, ambient water quality should be monitored, especially at sites of great mussel diversity, to determine if major ion concentrations are at or above levels that freshwater mussels can tolerate. For example, Gillis [5] found that chloride concentrations measured at mussel beds in Canada periodically reached acutely toxic levels for the mussel species tested in that study. In addition, Prosser et al. [9] found that several rivers in Ontario showed a risk of reaching chronically toxic levels of major ions to freshwater mussels. Monitoring of ambient chloride, potassium, and other major ions is especially needed during times of the year when freshwater mussels are releasing glochidia since glochidia sensitivity to major ions appears to be similar to juveniles.

\section{Conclusions}

In summary, freshwater mussels appear to be among the most sensitive organisms to at least some major ions, such as chloride and potassium. Hardness may provide some amelioration of toxic effects of chloride (and possibly other ions). Finally, $\mathrm{NaCl}$ toxicity tests indicate that commonly tested freshwater mussel species may be generally protective of rare species; however, additional testing is needed to confirm this finding. Further testing with variation in other water quality parameters would add to the environmental realism and application of standardized toxicity tests.

Author Contributions: Conceptualization, R.B.B. and R.E.R.; methodology, R.B.B., B.K.R., D.L.H. and R.E.R.; software, R.B.B. and B.K.R.; validation, R.B.B.; resources, R.B.B.; data curation, D.L.H.; writing-original draft preparation, R.B.B., B.K.R. and D.L.H.; writing-review and editing, R.B.B. and D.L.H.; visualization, R.B.B., B.K.R. and D.L.H.; supervision, R.B.B. and R.E.R.; project administration, R.B.B.; funding acquisition, R.B.B. All authors have read and agreed to the published version of the manuscript.

Funding: Funding for this work was provided by Equilibrium Environmental, Inc. through service contract number 2016PT123 with the University of Georgia Research Foundation, Inc. (Athens, GA, USA) and through a cooperative agreement between Department of Energy Office of Environmental Management and University of Georgia Research Foundation under award number DE-EM0004391. 
Institutional Review Board Statement: All testing was conducted under the auspices of the University of Georgia Institutional Animal Care and Use Committee, Animal Use Permit \#A2017 06-009-R1 and Georgia Department of Natural Resources Scientific Collection permit \#029, CN \#24822. Work with Hamiota altilis was covered by U.S. Fish and Wildlife Service Endangered Species permit \#130300-5.

Data Availability Statement: Data is available upon request from the corresponding author.

Acknowledgments: We thank all who provided brooding mussels for this work, including Chris Barnhart, Rachel Hoch, Paul Johnson, Monte McGregor, and Jim Stoeckel. Adrian Moore provided valuable assistance in the lab, and study design was assisted by Ian McIvor and Anthony Knafla.

Conflicts of Interest: The authors collaborated with the funders to design the study; funders were not involved in the collection, analyses or interpretation of data; in the writing of the manuscript, or in the decision to publish the results.

Disclaimer: This report was prepared as an account of work sponsored by an agency of the United States government. Neither the United States Government nor any agency thereof, nor any of their employees, makes any warranty, express or implied, or assumes any legal liability or responsibility for the accuracy, completeness, or usefulness of any information, apparatus, product, or process disclosed, or represents that its use would not infringe privately owned rights. Reference herein to any specific commercial product, process, or service by trade name, trademark, manufacturer, or otherwise does not necessarily constitute or imply its endorsement, recommendation, or favoring by the United States Government or any agency thereof. The views and opinions of authors expressed herein do not necessarily state or reflect those of the United States Government or any agency thereof.

\section{References}

1. Goodfellow, W.L.; Ausley, L.W.; Burton, D.T.; Denton, D.L.; Dorn, P.B.; Grothe, D.R.; Heber, M.A.; Norberg-King, T.J.; Rodgers, J.H.J. Major ion toxicity in effluents: A review with permitting recommendations. Environ. Toxicol. Chem. 2000, 19, 175-182. [CrossRef]

2. Cantafio, L.J.; Ryan, M.C. Quantifying baseflow and water-quality impacts from a gravel-dominated alluvial aquifer in an urban reach of a large Canadian river. Hydrogeol. J. 2014, 22, 957-970. [CrossRef]

3. Kaushal, S.S.; Groffman, P.M.; Likens, G.E.; Belt, K.T.; Stack, W.P.; Kelly, V.R.; Band, L.E.; Fisher, G.T. Increased salinization of freshwater in the northeastern United States. Proc. Natl. Acad. Sci. USA 2005, 102, 13515-13520. [CrossRef]

4. Griffith, M.B. Toxicological perspective on the osmoregulation and ionoregulation physiology of major ions by freshwater animals: Teleost fish, crustacea, aquatic insects, and Mollusca. Environ. Toxicol. Chem. 2016, 36, 576-600. [CrossRef] [PubMed]

5. Gillis, P.L. Assessing the toxicity of sodium chloride to the glochidia of freshwater mussels: Implications for salinization of surface waters. Environ. Pollut. 2011, 159, 1702-1708. [CrossRef]

6. Todd, A.K.; Kaltenecker, M.G. Warm season chloride concentrations in stream habitats of freshwater mussel species at risk. Environ. Pollut. 2012, 171, 199-206. [CrossRef] [PubMed]

7. Nogueira, L.S.; Bianchini, A.; Wood CMLordo, V.L.; Higgins, S.; Gillis, P. Effects of sodium chloride exposure on ion regulation in larvae (glochidia) of the freshwater mussel Lampsilis fasciola. Ecotoxicol. Environ. Safe 2015, 122, 477-482. [CrossRef]

8. Clements, W.H.; Kotalik, C. Effects of major ions on natural benthic communities: An experimental assessment of the US Environmental Protection Agency aquatic life benchmark for conductivity. Freshwater Sci. 2016, 35, 126-138. [CrossRef]

9. Prosser, R.; Rochfort, Q.; Mcinnis RExall, K.; Gillis, P. Assessing the toxicity and risk of salt-impacted winter road runoff to the early life stages of freshwater mussels in the Canadian province of Ontario. Environ. Pollut. 2017, 230, 589-597. [CrossRef]

10. Wang, N.; Ivey, C.D.; Dorman, R.A.; Ingersoll, C.G.; Steevens, J.; Hammer, E.J.; Bauer, C.R.; Mount, D.R. Acute toxicity of sodium chloride and potassium chloride to a unionid mussel (Lampsilis siliquoidea) in water exposures. Environ. Toxicol. Chem. 2018, 37, 3041-3049. [CrossRef]

11. Haag, W.R.; Williams, J.D. Biodiversity on the brink: An assessment of conservation strategies for North American freshwater mussels. Hydrobiologia 2014, 735, 45-60. [CrossRef]

12. Bringolf, R.B.; Cope, W.G.; Mosher, S.; Barnhart, M.C.; Shea, D. Acute and chronic toxicity of technical-grade pesticides to glochidia and juveniles of freshwater mussels (Unionidae). Environ. Toxicol. Chem. 2007, 26, 2086-2093. [CrossRef] [PubMed]

13. Cañedo-Argüelles, M.; Kefford, B.J.; Piscart, C.; Prat NSchäfer, R.B.; Schulz, C. Salinisation of rivers: An urgent ecological issue. Environ. Pollut. 2013, 173, 157-167. [CrossRef] [PubMed]

14. Beggel, S.; Geist, J. Acute effects of salinity exposure on glochidia viability and host infection of the freshwater mussel Anodonta anatina (Linnaeus, 1758). Sci. Total Environ. 2015, 502, 659-665. [CrossRef] [PubMed]

15. Ciparis, S.; Phipps, A.; Soucek, D.J.; Zipper, C.E.; Jones, J.W. Effects of environmentally relevant mixtures of major ions on a freshwater mussel. Environ. Pollut. 2015, 207, 280-287. [CrossRef] [PubMed] 
16. Wang, N.; Ivey, C.D.; Ingersoll, C.G.; Brumbaugh, W.G.; Alvarez, D.; Hammer, E.J.; Bauer, C.R.; Augspurger, T.; Raimondo, S.; Barnhart, M.C. Acute sensitivity of a broad range of freshwater mussels to chemicals with different modes of toxic action. Environ. Toxicol. Chem. 2017, 36, 786-796. [CrossRef] [PubMed]

17. Committee on the Status of Endangered Wildlife in Canada (COSEWIC). 2010. Available online: https:/ / wildlife-species.canada. $\mathrm{ca} /$ species-risk-registry/species/speciesDetails_e.cfm?sid=583 (accessed on 23 July 2021).

18. Cummings, K.; Cordeiro, J. Lampsilis fasciola. The IUCN Red List of Threatened Species 2012: E.T189279A1922805. 2012. Available online: https:/ / www.iucnredlist.org/species/189279/1922805 (accessed on 15 October 2021).

19. Cummings, K.; Cordeiro, J. Hamiota altilis. The IUCN Red List of Threatened Species 2012: E.T11250A502085. 2012. Available online: https:/ / www.iucnredlist.org/species/11250/502085 (accessed on 15 October 2021).

20. American Society of Testing and Materials (ASTM). Standard Guide for Conducting Laboratory Toxicity Tests with Freshwater Mussels. In Annual Book of ASTM Standards; ASTM: West Conshohocken, PA, USA, 2013; p. 52.

21. American Public Health Association (APHA). Standard Methods for the Examination of Water and Wastewater; American Public Health Association: Washington, DC, USA, 1995.

22. Smith, M.E.; Lazorchak, J.M.; Herrin, L.E.; Brewer-Swartz, S.; Thoeny, W.T. A reformulated, reconstituted water for testing the freshwater amphipod, Hyalella azteca. Environ. Toxicol. Chem. 1997, 16, 1229-1233. [CrossRef]

23. Mount, D.R.; Gulley Hockett, J.R.; Garrison, T.D.; Evans, J.M. Statistical models to predict the toxicity of major ions to Ceriodaphnia dubia, Daphnia magna and Pimephales promelas (fathead minnows). Environ. Toxicol. Chem. 1997, 16, 2009-2019. [CrossRef]

24. Elphick, J.R.F.; Bergh, K.D.; Bailey, H.C. Chronic toxicity of chloride to freshwater species: Effects of hardness and implications for water quality guidelines. Environ. Toxicol. Chem. 2011, 30, 239-246. [CrossRef]

25. Soucek, D.J.; Linton, T.K.; Tarr, C.D.; Dickinson, A.; Wickramanayake, N.; Delos, C.G.; Cruz, L.A. Influence of water hardness and sulfate on the acute toxicity of chloride to sensitive freshwater invertebrates. Environ. Toxicol. Chem. 2011, 30, 930-938. [CrossRef]

26. Cope, W.G.; Bringolf, R.B.; Buchwalter, D.B.; Newton, T.J.; Ingersoll, C.G.; Wang, N.; Augspurger, T.; Dwyer, F.J.; Barnhart, M.C.; Neves, R.J.; et al. Differential exposure, duration, and sensitivity of unionoidean bivalve life stages to environmental contaminants. J. N. Am. Benthol. Soc. 2008, 27, 451-462. [CrossRef]

27. U.S. Environmental Protection Agency (USEPA). Ambient Water Quality Criteria for Chloride-1988: U.S. Environmental Protection Agency Office of Water Regulations and Standards 440/5-88-001; U.S. Environmental Protection Agency (USEPA): Washington, DC, USA, 1988; 47p.

28. Canadian Council of Ministers of the Environment (CCME). Canadian Water Quality Guidelines: Chloride Ion. Scientific Criteria Document; Canadian Council of Ministers of the Environment: Winnipeg, MB, Canada, 2011.

29. Fritts, A.K.; Barnhart, M.C.; Bradley, M.; Liu, N.; Cope, W.G.; Hammer, E.; Bringolf, R.B. Assessment of toxicity test endpoints for freshwater mussel larvae (glochidia). Environ. Toxicol. Chem. 2014, 33, 199-207. [CrossRef] [PubMed] 